Palliative and End of Life Care Research Group, Population Health Sciences, Bristol Medical School, University of Bristol, UK

lucy.selman@bristol.ac.uk Cite this as: $B M J 2021 ; 374: \mathrm{n} 1803$ http://dx.doi.org/10.1136/bmi.n1803 Published: 10 August 2021
ESSAY

\section{Covid grief has cracked us open: how clinicians respond could reshape attitudes to bereavement-an essay by Lucy Selman}

People working in healthcare experience grief professionally as well as personally and societally. Attitudinal shifts are needed, argues Lucy Selman, to improve access to formal and informal support and make grief a less lonely experience. Doctors' openness and willingness to show vulnerability could help

\section{Lucy Selman associate professor}

Grief and death have something crucial in common: an incidence of $100 \%$. The ache of grief is natural and unavoidable as we face the losses of everyday life-separation, serious illness, injury-and the pain of close bereavement, whether sudden or expected. Death and grief can come upon us at any time, regardless of whether our day job is saving lives.

The covid-19 pandemic starkly shows grief's ubiquity: some four million people have died globally, leaving over 35 million people bereaved. ${ }^{1}$ At least 115000 health workers are estimated to have died from covid-19. ${ }^{2}$ The horror of loss is writ large each day in newspapers worldwide ${ }^{34}$ and on social media. ${ }^{5}$

The grief entailed in practising medicine has never been so clear, pictured in the faces of exhausted nurses and doctors, the marks from their masks deep and red. The pandemic has raised barriers for grieving people seeking support and laid bare the necessity of better bereavement services-as well as highlighting the need for us all to make space for grief, other people's and our own. Clinicians have an important role to play in helping bereaved people; they are also particularly exposed to grief, and openly acknowledging this could help shift societal attitudes.

\section{Death at the heart of public discourse}

Grief is the emotional process we go through when losing someone or something important to us. Mourning is an expression of grief, a social process and period in which we show grief visibly, which varies across cultures, religions, and history. Bereavement is the experience of having recently lost an important person through death, often characterised by grief and mourning.

Grief can also be felt with other losses or changes in circumstances, including all those caused by the pandemic. Covid-19 has brought grief and death to the heart of public discourse and huge changes to our social circumstances. Regardless of whether we have been personally bereaved during the pandemic, we have lived intimately alongside death, loss, and uncertainty for a long time, and this is likely to have affected us all. ${ }^{6}$

Grief is a natural part of life and not in itself a pathology requiring medical intervention. In bringing us face to face with our mortality-our insignificance in the scale of things and the inevitability of change-grief can be revelatory. ${ }^{7}$ Some people see the world anew; with time, grief can illuminate the joy and beauty of life, bringing focus and meaning where they were lacking. Grief can also lead to courage and action, ${ }^{8}$ as well as to works of art. ${ }^{910}$

\section{Emotional and health effects}

Bereavement can be one of life's most challenging events. An intensely emotional and disruptive period often follows a close bereavement. Deep sadness, yearning, confusion, isolation, despair, ${ }^{11}$ and a heightened risk of health problems are common. ${ }^{12}$ parental death in childhood was associated with higher all cause mortality into early adulthood, explained at least in part by the long term effects of parental death on health and social wellbeing. ${ }^{13}$ Bereavement can result in increased use of medication and healthcare, including more admissions to hospital, as well as nutritional and sleep problems and financial difficulties. ${ }^{12} 14$

Although many people suffer severely in early bereavement, and adjustment can take years rather than months, ${ }^{14}$ most bereaved people eventually adapt well. Over time, grief becomes less intrusive and more integrated into life, as the reality of the death is comprehended and accepted, and its consequences appreciated. ${ }^{11}$ But an estimated 10\% ${ }^{15}$ of bereaved people are diagnosed as having "prolonged grief disorder" ${ }^{\text {: }}$ : pervasive preoccupation with the dead person for at least six months, with intense emotional pain and substantially impaired functioning. Such grief persists beyond the norms for the person's social, cultural, or religious context and becomes abnormally persistent and increasingly debilitating over time. ${ }^{13}$ Targeted specialist individual or group psychotherapy is recommended. ${ }^{17-19}$

\section{Covid-19's cruel effect on grieving}

The covid-19 pandemic has brought profound challenges for bereaved people, including poor experiences at the end of life, limited contact in the days before death, being unable to say goodbye to their loved one in person, limited contact with close friends and relatives, social isolation, and loneliness, ${ }^{20-22}$ the effects of which are being researched. ${ }^{20} 23$
In a nationwide cohort study across three countries, 
Before the pandemic, an estimated $10 \%$ of people needed specialist mental health support after bereavement, and 30\% benefited from bereavement support. ${ }^{24}$ After covid-19, extrapolating from research in motor neurone disease, researchers have suggested increases to $20 \%$ and 50\%, respectively. ${ }^{25} 26$

Bereaved people often experience problems getting the right support. There are persistent inequalities and barriers in accessing mental health and bereavement services, including lack of information and knowledge of how to get support and discomfort or reluctance to seek help from services. ${ }^{27}$ Limited outreach by bereavement services, unawareness of available support, and a lack of culturally competent services are specific barriers for people from ethnic minority communities. ${ }^{28-30}$

The prevalence and effects of such barriers are likely to have worsened during the pandemic, which has had a devastating and disproportionate effect on disadvantaged, black, Asian, and ethnic minority communities ${ }^{31}$ and people with disabilities. ${ }^{32}$

\section{GPs play a crucial role}

Our UK survey of 711 people bereaved during the pandemic shows the need for psychological and emotional support. ${ }^{23}$ Most respondents had not sought support from bereavement services $(59 \%)$ or their general practitioner $(60 \%)$. Of those who had sought support, over half experienced difficulties accessing bereavement services $(56 \%)$ and GP support $(52 \%)$. Half (51\%) reported high or severe vulnerability in grief, and three quarters of this group were not accessing formal bereavement or mental health support.

Disparities between the amount of formal support available and the volume of people who need it have been identified before and during the pandemic, ${ }^{273334}$ and there is a clear need for pandemic specific, appropriate support to meet the needs of people bereaved in these difficult circumstances. Providing such support is likely to require integrated statutory, voluntary, and community services designed to meet the needs of diverse communities, with healthcare providers including GPs playing a crucial role in signposting to services as well as providing generalist bereavement support.

To overcome attitudinal barriers to accessing support, services need to be advertised proactively to all communities and groups that could benefit. ${ }^{35}$ There also needs to be investment in different types of bereavement support, including for people with specific characteristics (such as LGBTQ+, black, and ethnic minority communities) or who have experienced specific types of bereavement, and in cultural competency training for bereavement support providers. ${ }^{29}$

The UK has a wide range of bereavement services (see https://www.thegoodgrieftrust.org and https://www.ataloss.org), but signposting is often poor. In our survey, $51 \%$ of bereaved respondents had not been given any information about bereavement services.

\section{"Saying the wrong thing"}

Bereaved people also experience barriers accessing support from family and friends, including lack of understanding and compassion and difficulties expressing feelings and needs. In a 2019 Sue Ryder opinion poll, half of 2189 respondents said that they feared "saying the wrong thing” to someone bereaved. ${ }^{27}$ Half said they didn't know what support to offer, and one in four would avoid talking to somebody bereaved, highlighting the embarrassment, discomfort, and fear of causing offence that many people in the UK feel about discussing death and grief.
In the pandemic context, $39 \%$ of bereaved respondents to our survey reported difficulties accessing support from family and friends, describing problems connecting and communicating, a lack of understanding and empathy, struggling without in-person contact, and disruption to collective mourning practices. ${ }^{23}$ The perceived uniqueness of pandemic bereavement and wider societal strains added to this sense of isolation.

As society begins to look beyond the pandemic, signs indicate a possible shift in public attitudes. In a recent national survey $(n=2097)$, weighted to represent UK adults, one in five adults reported feeling more comfortable talking about grief, $47 \%$ felt more compassionate towards people who are grieving than before the pandemic, and 54\% agreed that the pandemic had encouraged them to think about their own mortality. ${ }^{36}$

Over 17 ooo people have watched Good Grief Festival events since its launch in October 2020 (www.goodgrieffest.com), indicating a thirst for knowledge and connection. We should harness this cultural shift to foster long term change, support communities, and make grief a less lonely experience. The independent UK Commission on Bereavement, launched on 15 June, will explore this context and make recommendations to strengthen support (https://bereavementcommission.mariecurie.org.uk/professionals/uk-commission-bereavement).

\section{Role of the clinician}

Before a death, clinicians have a central role in supporting a patient's family and friends. The circumstances of a death and the communication and support provided are important determinants of bereavement outcomes. Although restrictions to control infection are essential during the pandemic, steps should be taken to limit their negative effects on individualised, person centred care, with in-person visits enabled as much as possible ${ }^{5237}$ and end-of-life care providers prioritised for personal protective equipment. ${ }^{38}$

A public health model is helpful in flagging the types of support beneficial for bereaved people, and where policy makers should direct their attention. ${ }^{39}$ Primary preventive interventions target all bereaved people; secondary interventions target people at risk of complications of bereavement; and tertiary interventions target people with "complicated grief" or prolonged grief disorder. The National Institute for Health and Care Excellence has adopted a similar model, ${ }^{40}$ which recommends informal support and information about the experience of bereavement and how to access other forms of support for all bereaved people; peer-to-peer and community group support, with referral to professionals as needed for people who need a more formal opportunity to review their experience of loss, but not necessarily with professionals; and specialist interventions such as mental health and psychological support services for the minority of people who require them.

Clinicians have a role at each level: knowing about, and referring to, appropriate services, ${ }^{33}$ providing information about grief, and helping to alleviate barriers to support and change social attitudes. Simply broaching the subject and acknowledging a patient's loss with simple words ("I'm so sorry") go a long way and show that bringing grief into the consultation room is acceptable. Recording a bereavement in patient records, asking how they are doing at their next appointment, and following up when patients are distressed are good ways to show ongoing concern and to reassure patients that their grief matters.

\section{The futility of medicine}

Yet clinicians can go further. For people working in healthcare, grief brings home the ultimate futility of medicine as a lifesaving 
endeavour. Despite the best efforts of doctors, we all eventually die. Grief teaches us that medicine is about so much more than extending life.

Accommodating the ubiquity of sadness, loss, and grief makes some separation and compartmentalisation seem inevitable, even a useful coping strategy, for those who practise medicine. Clinicians are often encouraged or required, overtly or implicitly, to disregard and not talk about their own grief in the name of efficient patient care. ${ }^{41}{ }^{42}$ Despite evidence of significant grief among clinicians, patient deaths are often not discussed.

But sequestering grief into the "private" realm outside of medical practice can have unintended negative consequences for clinicians and patients and their families, rendering us all more alone. Denying grief, hiding it away, hiving it off to a personal self, distinct from the professional, is to deny its place in life and to deny our humanity. In the context of a pandemic in which colleagues, patients, and loved ones have died, leaving no room at the table for grief renders life inauthentic.

Working with death and grief elides professional barriers. It urges us to bring our vulnerability with us, meeting the patient as a person but also, crucially, bringing our own person with us. That does not mean burdening patients with our own suffering or failing to maintain helpful boundaries. Rather, responding with compassion towards patients requires us to understand and respect our own need to process emotions. 43

Grief prompts us to consider how we treat ourselves as well as how we treat the person in front of us professionally. Being open about our own experiences of grief, and showing the strength of vulnerability, is a powerful statement to patients, carers, and colleagues that can help shift society's attitude to grief. Individually, this can bring about a deepening and maturity of medical practice. Bringing the insights that grief affords into our professional and personal lives could have huge personal and societal benefits.

\section{Biography}

Lucy Selman is a social scientist at the University of Bristol specialising in advanced disease, end-of-life care, and bereavement research. She is co-leading a UK research study on bereavement during the covid-19 pandemic. Motivated by her personal experiences of bereavement as well as her research, she founded the free Good Grief Festival in 2020.

Provenance and peer review: Commissioned; not externally peer reviewed.

Competing interests: I have read and understood BMJ policy on declaration of interests and declare the following interests: I receive grant funding from the National Institute of Health Research, the Economic and Social Research Council, and the Wellcome Trust, am on the steering group of the UK Commission on Bereavement, and am the founding director of Good Grief Festival.

1 Verdery AM, Smith-Greenaway E, Margolis R, Daw J. Tracking the reach of COVID-19 kin loss with a bereavement multiplier applied to the United States. Proc Natl Acad Sci U S A 2020;117:17695-701. . doi: 10.1073/pnas.2007476117 pmid: 32651279

2 World Health Organization. Director-General's opening remarks at the World Health Assembly-24 May 2021. 2021. https://www.who.int/director-general/speeches/detail/director-general-sopening-remarks-at-the-world-health-assembly---24-may-2021.

3 Sowden R, Borgstrom E, Selman LE. "It's like being in a war with an invisible enemy": a document analysis of bereavement due to covid-19 in UK newspapers. PLoS One 2021;16:e0247904. doi: 10.1371/journal.pone.0247904 pmid: 33661955

4 Selman LE, Sowden R, Borgstrom E. "Saying goodbye” during the covid-19 pandemic: a document analysis of online newspapers with implications for end of life care. Palliat Med 2021;35:1277-87. . doi: 10.1177/02692163211017023 pmid: 34015978

5 Selman LE, Chamberlain C, Sowden R, etal. Sadness, despair, and anger when a patient dies alone from covid-19: a thematic content analysis of Twitter data from bereaved family members and friends. Palliat Med 2021;35:1267-76 . doi: 10.1177/02692163211017026 pmid: 34016005

6 James A. Planning for the long term impact of covid-19 on mental health. BMJ2021. https://blogs.bmj.com/bmj/2021/02/01/adrian-james-planning-for-the-long-term-impact-of-covid19-on-mental-health/
Michael C, Cooper M. Post-traumatic growth following bereavement: a systematic review of the literature. Couns Psychol Rev2013;28:18-33.

8 Sarner M. Post-traumatic growth: the woman who learned to live a profoundly good life after loss. Guardian 2021 May 11. https://www.theguardian.com/lifeandstyle/2021/may/11/post-traumatic-growth-the-woman-who-learned-to-live-a-profoundly-good-life-after-loss.

9 Yamamoto M. Motoi-Works. 2021. https://www.motoi-works.com/about.

10 Washington P. Poems of Mourning. Everyman's Library, 1998

11 Shear MK. Grief and mourning gone awry: pathway and course of complicated grief. Dialogues Clin Neurosci 2012;14:119-28. . doi: 10.31887/DCNS.2012.14.2/mshear pmid: 22754284

12 Stroebe M, Schut H, Stroebe W. Health outcomes of bereavement. Lancet 2007;370:1960-73 . doi: 10.1016/S0140-6736(07)61816-9 pmid: 18068517

13 Li J, Vestergaard M, Cnattingius S, etal. Mortality after parental death in childhood: a nationwide cohort study from three Nordic countries. PLoS Med 2014;11:e1001679. doi: 10.1371/journal.pmed.1001679 pmid: 25051501

14 Stroebe M, Stroebe W, Schut H, Boerner K. Grief is not a disease but bereavement merits medica awareness. Lancet 2017;389:347-9. . doi: 10.1016/S0140-6736(17)30189-7 pmid: 28137681

15 Lundorff M, Holmgren H, Zachariae R, Farver-Vestergaard I, O'Connor M. Prevalence of prolonged grief disorder in adult bereavement: A systematic review and meta-analysis. J Affect Disord 2017;212:138-49. . doi: 10.1016/j.jad.2017.01.030 pmid: 28167398

16 World Health Organization. International classification of diseases for mortality and morbidity statistics (11th Revision). 2018. https://www.who.int/standards/classifications/classification-ofdiseases.

17 Zisook S, Shear MK, Reynolds CF, etal. Treatment of complicated grief in survivors of suicide loss: a HEAL report. J Clin Psychiatry 2018;79:17m11592. doi: 10.4088/JCP.17m11592 pmid: 29617064

18 Shear MK, Reynolds CF, 3rdSimon NM, etal. Optimizing treatment of complicated grief: a randomized clinical trial. JAMA Psychiatry 2016;73:685-94. doi: 10.1001/jamapsychiatry.2016.0892 pmid: 27276373

19 Mason TM, Tofthagen CS, Buck HG. Complicated grief: risk factors, protective factors, and interventions. J Soc Work End Life Palliat Care 2020;16:151-74. doi: 10.1080/15524256.2020.1745726 pmid: 32233740

20 Harrop EFD, Longo M, Goss S, et al. Supporting people bereaved during covid-19: study report 1. 2020. https://www.researchgate.net/publication/348408939_Supporting_people_bereaved_during_COVID-19_Study_Report_1_Preliminary_results_from_a_survey_of_people_be reaved_in_the_UK_during_the_pandemic_Background

21 Strang P, Bergström J, Martinsson L, Lundström S. Dying from covid-19: loneliness, end-of-life discussions, and support for patients and their families in nursing homes and hospitals. a national register study. J Pain Symptom Manage 2020;60:e2-13. doi: 10.1016/j.jpainsymman.2020.07.020 pmid: 32721500

22 Hanna JR, Rapa E, Dalton LJ, etal. A qualitative study of bereaved relatives' end of life experiences during the COVID-19 pandemic. Palliat Med 2021;35:843-51. doi: 10.1177/02692163211004210 pmid: 33784908

23 Harrop E, Goss S, Farnell D, etal. Support needs and barriers to accessing support: Baseline results of a mixed-methods national survey of people bereaved during the COVID-19 pandemic.medRxiv 2021. https://www.medrxiv.org/content/10.1101/2021.06.11.21258575v1

24 Rumbold B, Aoun S. An assets-based approach to bereavement care. Bereave Care 2015;34:99-102. doi: 10.1080/02682621.2015.1115185

25 Aoun SM, Kissane DW, Cafarella PA, etal. Grief, depression, and anxiety in bereaved caregivers of people with motor neurone disease: a population-based national study. Amyotroph Lateral Scler Frontotemporal Degener 2020;21:593-605. doi: 10.1080/21678421.2020.1790610 pmid: 32668960

26 Public health approaches to bereavement care-through the lens of the pandemic. Second International Research Seminar on Public Health Research in Palliative Care; 2020 17-18 November 2020; Online.

27 Ryder S. A Better Grief London. Sue Ryder, 2019.

28 Mayland CR, Powell R, Clarke G, etal. Bereavement care for ethnic minority communities: A systematic review of access to, models of, outcomes from, and satisfaction with, service provision.MedRxiv 2021. https://www.medrxiv.org/content/10.1101/2021.02.13.21251679v1

29 Murray K. National Mapping of BAME Mental Health Services. London, 2020

30 Bignall T, Jeraj S, Helsby E, etal. Racial disparities in mental health: Literature and evidence review Race Equality Foundation, 2019.

31 Public Health England. Disparities in the risk and outcomes of COVID-19 Public Health England, 2020.

32 Shakespeare T, Ndagire F, Seketi QE. Triple jeopardy: disabled people and the COVID-19 pandemic Lancet 2021;397:1331-3. . doi: 10.1016/S0140-6736(21)00625-5 pmid: 33740474

33 Wakefield D, Fleming E, Howorth $\mathrm{K}$, etal. Inequalities in awareness and availability of bereavement services in North-East England. BMJ Support Palliat Care 2020:bmjspcare-2020-002422. doi: 10.1136/bmjspcare-2020-002422. pmid: 32967861

34 Pearce C, Honey JR, Lovick R, etal. "A silent epidemic of grief": a survey of bereavement care provision in the UK and Ireland during the covid-19 pandemic. BMJ Open 2021;11:e046872. doi: 10.1136/bmjopen-2020-046872 pmid: 33658262 
35 Harrop E, Mann M, Semedo L, Chao D, Selman LE, Byrne A. What elements of a systems' approach to bereavement are most effective in times of mass bereavement? A narrative systematic review with lessons for covid-19. Palliat Med 2020;34:1165-81. doi: 10.1177/0269216320946273 pmid: 32736489

36 Co-op Funeral Care. Coronavirus pandemic helps 24 million adults become more compassionate towards those who are grieving. 2021. https://www.co-operative.coop/media/news-releases/coronavirus-pandemic-helps-twenty-four-million-adults-become-more-compassionate

37 Mayland CR, Hughes R, Lane S, etal. Are public health measures and individualised care compatible in the face of a pandemic? A national observational study of bereaved relatives' experiences during the COVID-19 pandemic. Palliat Med 2021;0:2692163211019885. doi: 10.1177/02692163211019885. pmid: 34053347

38 Oluyase A, Hocaoglu M, Cripps R, etal. The challenges of caring for people dying from COVID-19: a multinational, observational study of palliative and hospice services (CovPall). J Pain Symptom Manage 2020; doi: 10.1016/j.jpainsymman.2021.01.138. pmid: 33556496

39 Aoun SM, Breen LJ, O'Connor M, Rumbold B, Nordstrom C. A public health approach to bereavement support services in palliative care. Aust N ZJ Public Health 2012;36:14-6. . doi: 10.1111/j.1753-6405.2012.00825.x pmid: 22313700

40 National Institute for Clinical Excellence. Guidance on cancer services: improving supportive and palliative care for adults with cancer. 2004. https://www. nice.org.uk/guidance/csg4

41 Bolier M, Doulougeri K, de Vries J, Helmich E. "You put up a certain attitude": a 6-year qualitative study of emotional socialisation. Med Educ 2018;52:1041-51. doi: 10.1111/medu.13650 pmid: 30058715

42 Rhodes-Kropf J, Carmody SS, Seltzer D, etal. “This is just too awful; I just can’t believe I experienced that...": medical students' reactions to their "most memorable" patient death. Acad Med 2005;80:634-40. . doi: 10.1097/00001888-200507000-00005 pmid: 15980079

43 Whitehead PR. The lived experience of physicians dealing with patient death. BMJ Support Palliat Care 2014:4:271-6. . doi: 10.1136/bmjspcare-2012-000326 pmid: 24644159

This article is made freely available for use in accordance with BMJ's website terms and conditions for the duration of the covid-19 pandemic or until otherwise determined by BMJ. You may use, download and print the article for any lawful, non-commercial purpose (including text and data mining) provided that all copyright notices and trade marks are retained. 